\title{
DIDÁCTICA DE LO HUMANO EN "VIAJE AL PORVENIR" Y "EL NIÑ̃ DEL CARRIZO" DE CÉSAR VALLEJO
}

\section{DIDACTICS OF HUMANITY IN “JOURNEY TO THE FUTURE” AND “THE CHILD OF THE REED” BY CESAR VALLEJO}

\author{
Elena Guichot-Muñoz ${ }^{1}$
}

\section{RESUMEN}

Este trabajo reflexiona sobre dos de los cuentos menos estudiados del autor peruano César Vallejo: Viaje al porvenir, y El niño del Carrizo. Entre 1935 y 1936, años en los que el poeta discurría por estéticas vanguardistas, aparecen estos dos relatos breves que muestran la esencia del ser humano a través de distintas estrategias textuales. En el primer cuento, Vallejo juega con el lenguaje del absurdo, con la comicidad y el acercamiento al cine satírico de Chaplin, en una crítica directa al capitalismo alienante. Mientras, en El niño del carrizo su prosa se estiliza, y la fauna y la flora vernácula se confunden con el dibujo del protagonista, en una bella restitución de un indigenismo que se acerca a una filosofía panteísta. El artículo revisa, por tanto, un concepto fundamental en la época: la alienación del individuo, y su contrario, la integración de lo humano en lo natural.

Palabras clave: Cesar Vallejo; humanismo; indigenismo; alienación; cuento.

\section{ABSTRACT}

This article examines two of the least studied tales of Peruvian author César Vallejo: Journey to the future, and The child of the reed. Between 1935 and 1936, years in which the poet ran through avant-garde aesthetic, these two short stories that show the essence of the human being through various textual strategies were published. In the first story, Vallejo plays with the language of the absurd, with comedy and a satirical approach to the films of Chaplin, to criticize directly the so-called alienating capitalism. In The child of the reed, his prose is stylized and vernacular fauna and flora confused with the drawing of the protagonist. Everything comes together in a beautiful restoration of an Indigenism that resembles a pantheistic philosophy. This article reviews a fundamental concept at the time: the alienation of the individual, and its opposite, the integration of humans in nature.

Keywords: Cesar Vallejo; humanism; Indigenism; alienation; tale.

Tipología: Artículo de Reflexión

Fecha de recepción: 04/05/2015

Fecha de aceptación: 23/07/2015

Como citar este artículo: Guichot-Muñoz, E. (2015). Didáctica de lo humano en Viaje al porvenir y El niño del carrizo, de César Vallejo. Jangwa Pana, 14, 125 - 135.

1. Docente del Departamento de Didáctica de la lengua y de la literatura y Filologías integradas, Universidad de Sevilla, España. Correo: eguichot1@us.es 


\section{INTRODUCCIÓN}

$E^{\prime}$ interés del análisis crítico de estos cuentos reside en el carácter literario peculiar que poseen ambas narraciones. El estilo y la temática de estos cuentos rompen con el trabajo poético anterior, dándonos muestra del manejo literario tan diverso de César Vallejo. Estos cuentos que datan de 1935 y 1936 se alejan de la prosa introspectiva de Escalas melografiadas, de su vocabulario intrincado y sus estructuras alambicadas, su trama sorpresiva, esotérica. Quedan atrás ya los trágicos sucesos que rodearon esa época; la muerte de su madre y el episodio carcelario en la vida de Vallejo motivan una crisis de conciencia que se verá reflejada en la estilística y la temática de su obra.

Sin embargo, en las fechas en que escribe estos cuentos el autor cambia de rumbo. Se sumerge en las ideas del marxismo y en la investigación del modelo soviético que inicia la Revolución Rusa, realiza tres viajes a Rusia entre 1928 y 1931, y se afilia al Partido Comunista de España. Estas actividades, entre otras, se verán reflejadas en su narrativa; desde la publicación de Tungsteno en 1931 hasta los Cuentos Cortos que trataremos a continuación, percibimos un viraje absoluto hacia las preocupaciones sociales y políticas de su tiempo. Le interesa la situación del hombre en su contemporaneidad, apuesta por un arte colectivo que despierte las conciencias de los pueblos, por ello aboga por las ideas marxistas que representan para él una praxis social capaz de modificar al hombre alienado, producto de la sociedad capitalista.

No obstante, su prosa no se limitará a representar un realismo social con fin didáctico y adoctrinador que emane de una ideología política, al contrario, el "arte socialista" al que se inscribe Vallejo responde un deseo universal de unión, que se manifiesta en su poema Masa; un compendio de intereses, emociones e ideas comunes que sustenta a la humanidad. Los personajes y la estructura narrativa de Vallejo no corresponden con arquetipos maniqueos, sino que entran en una "dialéctica múltiple y cambiante, de características y personalidades propias, dentro de las circunstancias históricas de un proceso muy concreto" (Vallejo, 2007, p.43). Antonio Merino, prologuista del libro citado previamente, describe de esa forma el leitmotiv de Vallejo: el sufrimiento de la masa obrera que lucha para acabar con la sociedad capitalista, que jerarquiza y cosifica al individuo. Aun así, ya David Sobrevilla (1994) aclaraba que estos cuentos, a pesar de sostener una crítica férrea al sistema social y cultural, se alejan del "arte bolchevique" -siguiendo la división "arte bolchevique"/"arte socialista" de González Vigil en el prólogo de la obra de César Vallejo El arte y la revolución (1992)-, que caracterizaba por ejemplo la narrativa de Paco Yunque. Este realismo socialista pasa a un segundo plano en estos cuentos, que se apartan del estilo sencillo, del esquematismo, y de la concepción ideológica de su narrativa anterior (GonzálezMontes, 2002), quizás por el distanciamiento del estalinismo que se dio en la penúltima etapa de su vida (Sobrevilla, 1994).

A pesar del tratamiento tan diverso de estos dos cuentos, el resultado de ambas lecturas es la expresión de una conciencia que reivindica lo humano por encima de todo, que incide sobre la falta de sentido de la vida en una sociedad en la que las relaciones sociales pierden sus valores primitivos, frente a la injusticia a la que se enfrentan día y noche. Quizás la exageración de sus formas: el estilo esperpéntico del primer cuento que analizamos, o la mística del personaje principal del segundo; sean intentos de aproximación hacia un problema que le preocupa desde sus inicios hasta el final de sus días: la conciencia natural de la humanidad frente a la inercia alienante del individuo por el artificio. Analizaremos críticamente entonces la materia y el fondo de estos cuentos, con el fin de resolver el modo de aproximación de Cesar Vallejo a esta temática a través de los cuentos. Cotejaremos asimismo con 
algunos poemas de la misma época para contrastar diversas maneras genéricas de enfrentarse a esta cuestión.

\section{DISCUSIÓN}

La quimera del hijo hombre: análisis crítico de Viaje al porvenir ${ }^{2}$

“Con el tiempo la Revolución creará una sociedad universal, sin fronteras, en que todos los hombres estén unidos por amor y trabajarán juntos como hermanos (...) Entonces el hombre superará el absurdo, dominará la naturaleza y controlará su destino" (Higgins, 1988, p. 238).

Esta cita es un compendio de los deseos que Vallejo pretendía ver reflejados en la sociedad. Lucha contra la mentalidad individualista, enajenante del sistema capitalista, para poder instalar una sociedad de colaboración colectiva, donde la solidaridad con los conciudadanos sea un valor inherente al individuo. Este cuento trata la historia de un matrimonio de conveniencia que se somete a los caprichos de un hacendado frío y tiránico, para conseguir escalar en la sociedad. Propondremos una división de este cuento en tres cuadros que explicaremos más adelante, y analizaremos la técnica de la que se sirve Vallejo para darnos un humorístico y a la vez trágico ejemplo del comportamiento enajenado de los individuos que componían la sociedad de su tiempo.

\section{Cuadro primero}

Esta escena comienza con el sobresalto del administrador en mitad de la noche. Nos presenta una noche de insomnio que sufre el matrimonio en medio de un absoluto silencio en el que sólo se escuchan los pensamientos de ambos. El narrador nos introduce a esta pareja: un matrimonio que se define como "un buen negocio"; el administrador se casa con una pariente lejana de su patrón, Eva,

2. Tomamos como referencia la obra citada: Narrativa completa de César Vallejo, edición de Antonio Merino, Akal, Madrid, 2007 para subir de categoría en la hacienda en la que trabaja. La racionalización numérica va a aparecer durante toda la escena: desde la puntualización de las horas que marca el reloj (advirtiendo que el administrador se tiene que levantar a las tres y media), hasta la minuciosa descripción de la subida de salario y de las "deferencias" que el patrón tuvo con él desde el casamiento; "tenía para él una sonrisa, por lo menos, a la semana", "una vez al mes, les estaba acordado a su mujer y a él, ir de visita a la casa-hacienda y comer en la mesa de los parientes pobres del patrón" (Vallejo, 2007, p. 353). La descripción carece de adjetivos valorativos o digresiones morales para mostrarnos la normalidad con la que estos personajes conciben estos hechos cotidianos. Este cuadro es una presentación de los personajes y del conflicto: el patrón "hombre duro, vanidoso y avaro" había prometido "la dádiva mayor" que esperaban impacientes los protagonistas del relato. Vallejo nos ofrece un dibujo de una sociedad oligárquica que nos recuerda al tiempo de la República Aristocrática que se dio en Perú durante los años 1899-1919, pues bien sabemos que el mundo campesino estaba condicionado por el sistema de gamonalismo que existía sobre todo en la Sierra Central y en la Sierra Sur. Este Estado Oligárquico se definía por la propiedad de tierras indudablemente (en este caso una hacienda), pero también por el apellido, por lazos de parentesco, es decir, "a lo que sería criterios estrictos de clase se añadían otros de tipo estamental, como rezago y herencia de la colonia" (Burga \& Flores, 1979, p. 88) ${ }^{3}$. El núcleo central de esta trama es una familia que se forma en torno a un interés: el ascenso social. En esta sociedad "las alianzas matrimoniales eran un mecanismo que aseguraba la pertenencia a una clase social" (Burga \& Flores, 1979, p. 98). Así, la familia pierde su carácter sacramental, su inmanencia para reducirse a un simple contrato beneficioso. Aquí comienza pues el absurdo, que se incrementará al existir la

3. En este texto se hace referencia al estado oligárquico de la República Aristocrática. Aunque no se haga referencia al espacio temporal del cuento podríamos decir que las características de la sociedad que describen estos autores coinciden con las del cuento, y además son contemporáneas al autor. 
posibilidad de recibir dinero del patrón si logran tener un hijo varón. Estamos pues ante un acto biológico, natural, que se ve cosificado al tratarse como un elemento económico ganancial, tal y como mencionan en el texto, el nacimiento se define como "la empresa de diez mil soles". Merino advierte al respecto de que:

Estamos en el ámbito de la necesidad alienante, donde los sentimientos se enajenan en "cosas" que se compran o se venden (...) Su vida no está pues, sujeta a los designios del destino, del azar, sino a las condiciones sociales, políticas y económicas que alimentan esa "enajenación" (Vallejo, 1976, p. 42) .

\section{Cuadro Segundo}

Este cuadro comienza con una escena en el comedor del patrón, acompañado de su mujer, el día que nace la hija del administrador. El diálogo desencadena el desarrollo posterior del nudo de la trama: el patrón, al enterarse de que "la criatura es una mujercita" se mofa de la incapacidad de Eva para "no hacé un muchacho hombre" (Vallejo, 2007, p. 354).

Es relevante destacar la caricaturización del despótico patrón. Vallejo le atribuye un lenguaje ridículo, un español chinesco que reproduce constantemente a causa de la relación de servidumbre que mantuvo desde su niñez con este grupo de inmigrantes, y que extiende al resto de obreros que le sirven, ya que todos son "económicamente inferiores", aunque ahora sean indígenas de la sierra. Los coolies fueron llevados al Perú en el siglo XIX como mano de obra barata, y eran considerados como el más bajo escalón de la sociedad. Realizaban las tareas más duras a cambio de un salario miserable que les llevaba a endeudarse de unos y de otros hasta llegar a vender cualquier

4. Esta cita hace referencia al cuento "Cera" que pertenece a Escalas. Consideramos que la situación de despojamiento de la vida de Chale, que sobrevive pendiente de su suerte, puede asemejarse a la enajenación de esta pareja que vive pendiente del acontecimiento azaroso de dar a luz un hombre para ganar la dádiva prometida. cosa: "no sólo comprometían sus escasos bienes (...) sino también sus seres más queridos, sus hijos y sus esposas, empeñando en las apuestas hasta su propia vida, sin saber jamás que esa vida hacía mucho tiempo que había dejado de pertenecerles" (Vallejo, 2007, p. 41). No es casual que haga referencia a este grupo, ya que la vida de los protagonistas también ha dejado de pertenecerles. Se igualan así en el escalafón más bajo los coolies, los indígenas de la Sierra del Perú y el mismo administrador de la hacienda. Todo se somete a los designios del patrón que mueve los hilos de sus vidas. La figura del patrón, sin embargo, se despoja de todo signo de autoridad competente, su lenguaje es absurdo ya que su padre fue un italiano advenedizo (veamos la paradoja de que es también un inmigrante como los coolíes), y su entorno no tiene ese tipo de idioma. No obstante, la intención de Vallejo es la de dibujar un personaje sin sentido ni lógica, con características físicas como "sus largas piernas gigantes", tal y como si saliera de una película de Chaplin o del propio esperpento de Valle Inclán. La referencia a Chaplin no es baladí, ya que además de las semejanzas evidentes con las imágenes y las escenas del cuento, sabemos que Vallejo escribió desde 1927 reseñas a obras cinematográficas, entre las que se destaca la anotación a La quimera de oro $^{5}$. Para Vallejo es "una sublime llamarada de inquietud política, una gran queja económica de la vida", "una obra maravillosa de la revolución" (Oviedo, 2003, p. 55). Gómez (2012) rescata la presencia de la estética de Chaplin en sus Poemas humanos y atiende a un aspecto que nos interesa por las semejanzas con este cuento: el uso del cuerpo en el "hombre-fábrica" (hombre en la acepción de ser humano): "Al igual que la máquina, el cuerpo se convierte en un artificio en el que los miembros realizan funciones de rendimiento económico y sólo son así valorados dentro del sistema de producción" (Gómez, 2012). La crítica ejemplifica este lenguaje con el poema titulado "Los desgraciados":

5. The Gold Rush se estrena en 1925, traducida por Vallejo como En pos del oro. «La pasión de Charles Chaplin» en Crónicas, Tomo II, pág. 231. 
Ya va a venir el día; da cuerda a tu brazo, búscate debajo del colchón, vuelve a pararte en tu cabeza, para andar derecho. Ya va a venir el día, ponte el saco (Vallejo, 2012b, p. 589).

Este poema habla sobre la esperanza revolucionaria, como señala González Vigil, pero en 1937, fecha de escritura del poema, Vallejo asume que el lenguaje cotidiano del ser humano está contagiado de la mecánica del "progreso" ("da cuerda a tu brazo"). Es necesario atender a las palabras del propio poeta en un artículo que escribió en 1931, donde hace alusión al aspecto del lenguaje en su sociedad contemporánea:

Estamos mudos en medio de nuestra verborrea incomprensible (...). La palabra- forma de relación social la más humana entre todas- ha perdido así toda su esencia y sus atributos colectivos (...). Nadie comprende a nadie. El interés del uno hasta un lenguaje que el interés del otro ignora y no entiende ¿Cómo van a entenderse nunca el patrón y el asalariado? (Vallejo, 1987, p. 434).

La capacidad que nos hace humanos va perdiendo su función original, en pos de un interés económico-social. Este lenguaje vacío, pre-fabricado, diríamos casi antisocial, se manifiesta a lo largo del cuento constantemente. Al principio observábamos un silencio que continúa hasta el final, cerrando en estructura circular el cuento. Este mutismo contrasta con los pensamientos abundantes que circulan por la mente de ambos protagonistas. Incluso los mensajes que reproducen carecen de intencionalidad semántica. Se refleja perfectamente en la siguiente escena: El administrador le confiesa a su esposa que expolia las pagas de los obreros para incrementar las ganancias del patrón, con la intención de caerle en gracia y recibir sus valiosas deferencias. La mujer, extrañada por el hecho de que los obreros no cobraran su trabajo exclama: “¡Pobrecitos!”. No obstante, este diálogo cae en el vacío ya que no se cuestiona la injusticia de la acción, y acaba pensando que la dádiva prometida por el futuro hijo "era una cosa completamente desinteresada y generosa" (Vallejo, 2007, p. 356).

Como vemos, en este mundo absurdo, las palabras se disfrazan, se ocultan, pierden su significado. Viven en "un nivel superficial sin percibir el absurdo de la existencia y creyendo que su vida tiene un sentido" (Higgins, 1988, p. 227). La acción maliciosa e injusta del administrador se ve como un hecho natural justificado por los intereses del matrimonio. Su meta es conseguir acabar con los apuros económicos y aparentar una posición más elevada que otras familias: “¿Por qué solamente los Herrera y los Ulecardo tenían derecho a pasear a Lima todos los años?".

En esta sociedad "los linderos de la hacienda eran también los límites del poder" (Burga \& Flores, 1979, p.89), del Estado Oligárquico. Los patrones ejercían un papel paternalista sobre sus trabajadores que "terminaba generando esa engañosa sensación de que dueños y trabajadores formaban parte de una misma familia" (Burga \& Flores, 1979, p.98). Este proceso también lo vemos en el fragmento en que la mujer del administrador recibe la maravillosa noticia de la cesión de la dádiva a cambio de hacer un hijo hombre: "Formulada la promesa del patrón, se apresuró a comunicarla directamente a su mujer, la cual, en su gran inconsciencia, vecina de un impudor casi cínico, recibió la noticia con saltos de alegría y entusiasmo". Coincidimos por tanto en la afirmación al respecto que reseña Rodríguez Peralta: "Aunque el concepto de raza está implícito en la estructura social, la atención de Vallejo se dirige al rígido sistema de clases usado en la hacienda" (Rodríguez-Peralta, 1984, p.442).

\section{Cuadro tercero}

Una estructura circular cierra la trama que vuelve a la noche de insomnio del matrimonio. Ahora se resuelven las causas de esa falta de sueño, pues sabemos que ambos elucubran sobre la necesidad imperiosa de procrear un hijo hombre. Describe 
en una digresión temporal las "noches ardidas de esfuerzo y ansiedad" en las que intentaron conseguir su objetivo. Nos presenta una humorística escena que podría insertarse como una auténtica pieza de cine mudo. Se desnaturaliza absolutamente el acto sexual, la animalidad de los instintos se sustituye por "un espasmo heroico y calculado, como un teorema de una raíz cúbica". Conocemos por la poesía de Vallejo que para él el acto sexual podía alcanzar la superación del absurdo, ya que "macho y hembra ascienden a una realidad trascendental en donde se fusionan en una nueva unidad" (Vallejo, 2007, p. 170). Pero, muy al contrario, en estas escenas se ve el distanciamiento absoluto de los protagonistas, que realizan la jocosa labor de adivinar si lograron la gestación de un hijo hombre. Así la enajenación del hombre es absoluta, pues incluso en un ámbito tan íntimo, donde lo humano roza con lo animal, el deseo se ve transformado en una necesidad económica. Tal y como dice Antonio Merino sobre el tema de la enajenación:

La "enajenación" del hombre habría que buscarla en el trabajo (que es su propia esencia), cuando lejos de afirmarlo lo cosifica y deshumaniza, y más si la situación es límite. Ésta se expresa en el plano de las relaciones sociales mediante un desdoblamiento (escisión) entre lo público y lo privado. La "enajenación" del individuo será mayor en la medida en que lo público absorba a los privado, lo anule" (Vallejo, 2007, p. 19).

El absurdo llega hasta el punto en que se desencadena la cólera de Arturo, el administrador, por la incapacidad para tener un hijo hombre. Un "bufido" y un movimiento brusco darán la señal a su mujer para saber en qué está pensando su marido. Así, reinician otro ardido esfuerzo para "no abandonar la empresa de diez mil soles", tomando el administrador a su mujer "a su turno", besándose por supuesto "sin pronunciar palabra".
La paradoja final es el desenlace desafortunado para el matrimonio ya que "la empresa abortó (...), Eva daba a luz a una mujercita". Así, el viaje se realiza alrededor del porvenir porque nunca llegaron a alcanzarlo tal y como esperaban. Sus sueños de noche y día se fraguan con la resolución de este misterio. El administrador y su esposa, Eva, con un nombre parlante que no necesita gran explicación, llevan a cabo su misión, pero la naturaleza les muestra la faz indomable del azaroso destino. Este cuento es una demostración de la habilidad de César Vallejo para presentarnos una historia donde lo ridículo, lo risible y lo serio se entremezclan, dando lugar a una escena absurda superficialmente, que en su significado último trasciende hacia las ideas del marxismo, que lucha contra el despojamiento del lado humano del individuo en la sociedad capitalista. Por ello dibuja estas marionetas que actúan fuera de todo sentido común. Merino nos avisa de que:

cuando el amor no es una exteriorización objetiva y, al mismo tiempo, la expresión subjetiva (liberada de las presiones morales) del ser total, entonces se transforma en un amor "enajenado", en un fetiche, idealización de esa individualidad encerrada en su soledad (Vallejo, 2007, p. 34).

El repliegue de los sentimientos a una quimera económica deshumaniza al hombre. César Vallejo creía en el amor como única fuente de salvación de la sociedad alienada. Por ello realiza este mundo al revés que representa la falta de valores en los tiempos modernos que le rodean. Estos tiempos modernos también comienzan a adquirir los tintes de la sociedad del espectáculo de Debord, y de ahí nuestra propuesta de dividir este análisis en cuadros, respondiendo a la estética teatral que se puede percibir en este cuento. La dinámica de los personajes, el empleo del flashback cinematográfico, la caricaturización de los personajes en sus estados de ánimo y en la comicidad de sus acciones, la presencia del 
diálogo, provocan una visualización de las escenas como si el autor tuviera una intención de su representabilidad. La influencia del cine también se puede observar en la caracterización de los personajes: una influencia claramente chaplinesca, la quimera del oro versión peruana:

Hay lugar para que algunos puedan preguntarse con todo el candor del mundo: Un señor, vestido de azul y calzado de marrón dos veces, se abotona cincuenta botones del traje, toma quince vehículos diversos, se quita $\mathrm{y}$ se pone el abrigo diez veces, que paga y espera veinte veces la vuelta, que lee tres periódicos y dos revistas ilustradas... ¿podrá tener tiempo para vivir siquiera un ligero instante espiritual, desinteresado, universal, puro en ese pícaro horario de New York o París? [...] (Vallejo, 1984, p. 10)

\section{La metamorfosis incaica: análisis crítico de El niño del carrizo}

Decía Alberto Flores Galindo (2008), que la paradoja de la utopía andina es que "han sido (...) sectores intermedios ni indios ni españoles, quienes repetidas veces han querido reconocerse en un supuesto rostro nacional" (p. 16). La utopía andina se erige como una forma de luchar contracorriente en un intento de reconstrucción de una identidad fragmentada. Una de las figuras literarias principales de este concepto es José María Arguedas, que consolida los valores sublimes de la población originaria del Perú, y universaliza el mundo andino a través del conocimiento de los elementos sensibles que lo componen: el río, las piedras, las cosas del mundo natural. Dentro de la genealogía previa que funda el Inca Garcilaso o Guamán Poma de Ayala se encuentra César Vallejo. Este cuento breve es un canto primoroso al vínculo entre la naturaleza y el hombre que despierta reverberaciones del mundo andino. Las descripciones que inundan el relato dan cabida a un minucioso y delicado estudio sobre la flora y la fauna vernácula en la que se inscribe el texto.
Se realiza una expedición hacia el interior de la naturaleza para conseguir un tipo especial de madera y carrizo con el fin de preparar las andas de la procesión de la Semana Santa. El narrador de la historia acompaña junto con su amigo Miguel a los dos hombres que encabezan la excursión.

Tras la presentación, la acción se detiene para deleitarnos con una descripción detallada del excepcional tipo de carrizo, que es considerado una verdadera reliquia en Semana Santa por su característico y penetrante aroma de "mística unción" (Vallejo, 2007, p. 347). La religión se funde con la naturaleza, las sensaciones que emana este carrizo poseen una fuerza telúrica capaz de provocar en la fauna "un éxtasis subconsciente" y que en las madrigueras chirríen "rabiosas oraciones". El léxico religioso no es gratuito en estas descripciones. Ya conocemos desde Heraldos negros el uso de vocabulario religioso, mayoritariamente cristiano, que Vallejo escoge para mostrar su espiritualidad intrínseca. También observamos en otros poemas la esencia de la filosofía del pitagorismo en su obsesión con los números (Yanuzzi, 2009). Sin embargo, también constatamos en este cuento su tendencia a resemantizar este léxico con tintes que van más allá de la doctrina católica, o de la herencia filosófica: se contrapone el uso decorativo y reemplazable cada año del carrizo en las festividades de la religión católica, con la exaltación de la flora y la fauna ante el mero contacto de esta caña especial. Vallejo nos va introduciendo en un panteísmo que se naturaliza en la descripción de la escena. Si el carrizo adquiere un carácter sagrado, lo humano también trascenderá hacia otra dimensión. Uno de los niños llamado Miguel, acompañado de sus perros, va a sufrir una integración absoluta con el medio. Su transformación se ve motivada por un "soplo de autonomía montaraz" (Vallejo, 2007, p. 344). En ese medio se siente como un hombre libre, descubre su fondo auténticamente animal hasta el punto de "alcanzar la sulfúrica traza de un cachorro". Lucha con los perros realizando 
las mismas acciones que llevaría a cabo uno de ellos de modo que los animales "parecían desconocerle". El papel de amo se aparta en este medio que comparten para confundirse ambos en seres animales con instintos primitivos (tal y como coger frutos desconocidos, atrapar otros animales, correr por los barrancos, morderse, saltar): "Al entrar en los puros dominios de la naturaleza, parecía moverse en un retozo exclusivamente zoológico" (Vallejo, 2007, p. 344). Es destacable decir que las imágenes asociativas no sólo se producen en la dicotomía hombre-animal, sino que se extienden a la flora en la que se insertan. Siguiendo un estudio crítico sobre este cuento, las síntesis asociativas se dan en más de un campo de significación: hombre-animal, hombre-vegetal, hombre-tierra-animal (Neale-Silva, 1987). La prosa adquiere además una velocidad plagada de verbos de movimiento, y una aglomeración de imágenes pictóricas y léxico autóctono que traza este "vértigo de locura" que provoca la inserción en la naturaleza: "el poeta se identifica con la tierra y su poesía se impregna de la fuerza telúrica del ambiente" (Driskell, 1978, p. 9).

La fraternidad entre Miguel y la jauría de canes culmina con una estampa que colma la fusión de estas tres fuerzas que provienen de la naturaleza: Miguel en posición arqueada bebe de "un chorro recóndito y azul, entre los matorrales", junto con los otros perros. La preciosa descripción une los campos léxicos del ojo del hombre y del animal junto con el movimiento de la onda del agua y de la "baba viscosa" del animal: "extraña anatomía la de Miguel, bebiendo en cuatro pies, el agua de la herbosa montaña" (Vallejo, 2007, p. 345).

El narrador entonces describe esta figura que aparentemente podría parecer "monstruosa", pero sólo responde a "el signo de todo lo que sale de la tierra por las plantas para tornar a ellas por las manos..." (Vallejo, 2007, p. 345). Aquí observamos la dicotomía entre civilización y barbarie que en numerosas ocasiones el autor vincula con el "mito del indio": la nobleza del indio, y el carácter barroco de la prosa eliminan una visión bárbara de esta anécdota. Aquello que mantiene su carácter virginal y primitivo, bello en todas sus formas, resulta ser deformado, desnaturalizado a los ojos del hombre civilizado. Sin embargo, mientras el resto de los excursionistas civilizados se dirigen a arrancar de su lugar de nacimiento el carrizo sagrado para crear una fiesta litúrgica religiosa alejada de estos entornos, Miguel ha vuelto al orden natural donde la humanidad convivía con el resto de los animales y se integraba en el medio que le rodeaba. Su actitud, empero, se califica a los ojos del narrador como "enajenada", "impulsado por un vértigo de locura", "figura monstruosa" (Vallejo, 2007, p. 345).

Esta estampa acaba con un dibujo que según varios autores recuerda a la figura del "molle": "árbol sagrado que atrapa con sus ramas en Janan pacha o mundo estelar, con su tallo el Kay pacha y con sus raíces el mundo latente de sus semillas y los muertos que no han muerto pero que descansan en el Uku pacha" (Villanes, 1988, p. 757). Este detalle conecta con la intencionalidad de Vallejo de conectar el mundo indígena incaico:

El valle primordial donde nació y transcurrió la niñez el poeta está a tres mil metros de altura sobre el nivel del mar (...) Allí la vida florece sin grandes calores ni frío rigurosos (...). La civilización inca, andina por excelencia, nació y alcanzó su esplendor en un medio natural similar (Villanes, 1988, p. 757).

Debemos recordar que en esta época Vallejo también escribió El reino de los Sciris, que es una bella narración sobre el imperio Inca, y sus costumbres locales, su cultura andina panteísta que "gira alrededor de la madre tierra (pacha-mama), de la Naturaleza y sus dioses", en palabras de Merino (Vallejo, 2007, p. 63). La carga simbólica reside en el hecho de que esta comunidad eminentemente agraria respetaba y temía este orden natural. En los tiempos en los que escribe este 
cuento, la naturaleza está subordinada a los avances tecnológicos que se necesiten para que la civilización progrese. Sin embargo, para Vallejo, el máximo desarrollo posible es el de la convivencia del ser humano con las fuerzas telúricas que lo crearon. El deseo se manifiesta claramente en su prosa cuando justifica la "figura monstruosa" de Miguel con el "espíritu terráqueo", e identifica dos bellas metáforas que marcan el simbolismo de Vallejo: el agua como "lágrimas rientes de la naturaleza", y la postura de Miguel "doblaba los pedestales ilíacos y extendía los brazos hacia delante", como la "línea victoriosa de los arcos" (parecida por otro lado a una asana del hatha yoga). Afirmaba Mariátegui que "el indio, por animista y bucólico, tienda a expresarse en símbolos e imágenes antropomórficas y campesinas" (Mariátegui,1975, p.330-331). En cierto modo, esta ambición del poeta se engancha con otras cuestiones tratadas ya por parte de otros autores a lo largo de los siglos: "Los coqueteos de Hugo con el ocultismo y la Cábala, los cuentos sobre la mandrágora y el golem de Achim von Arnim traducidos por Gautier en 1856 como Contes bizarres que presentaban ya un mundo en donde el sueño y lo real se yuxtaponían hasta confundirse" (Alazraki, 1972, p.33). Estos ejercicios que confluyen en el romanticismo y posteriormente en las vanguardias, confluyen en este cuento de Vallejo como un deseo de infinito, de transmutación del ser humano en parte de la naturaleza. Pasamos de la simbología católica de la Semana Santa con la que comienza el cuento: la procesión, la "inmemorial liturgia"; hasta el signo del infinito: "Miguel hacía así el signo de todo lo que sale de la tierra por las plantas, para tornar a ella por las manos...". Además, tipográficamente cierra el cuento con unos puntos suspensivos que reafirman esta interpretación. Antonio Merino, en el prólogo a la obra de Vallejo, resume de la siguiente forma la esencia que se transpira: "Ese cuadrúpedo intensivo de las cuatro conciencias señala lo animal, lo orgánico y lo material del sujeto (...) Su superación vendrá en años posteriores (1927-1938) por una nueva conciencia" (Vallejo, 2007, p. 10).

Por lo tanto, el indigenismo de Vallejo no se concibe como un acercamiento a lo regional, sino más bien como un intento de unir a todos los humanos en un estado primitivo en el que todos éramos iguales ante la poderosa fuerza de la naturaleza. En palabras de José Carlos Mariátegui:

Hay en Vallejo un americanismo genuino y esencial; no un americanismo descriptivo y localista. Vallejo no recurre al folklore. La palabra quechua, el giro vernáculo, no se incluyen artificiosamente en su lenguaje, son el producto espontáneo, célula propia, elemento orgánico (Mariátegui, 1975, p.248).

Es destacable la maravillosa plasticidad del lenguaje, que nos describe las escenas como si fueran esculturas en movimiento, como una de las metamorfosis de Ovidio, Miguel se arquea cual estatua:

Miguel doblaba los pedestales ilíacos y extendía los brazos hacia delante, hasta dar las manos en la tierra (...) Violentándose a tal ademán, las manos en un rol de nuevos pies, asentado en la tierra por medio de dos órdenes de columnas, Miguel modelaba la línea victoriosa de los arcos (Vallejo, 2007, p. 345).

Recordamos la figura victoriosa de Dafne transformada en laurel para no perder su virginidad a manos del dios Apolo. Llama a su amado padre que le transforma en esta hoja de la victoria. Quizás Miguel quiera quedarse convertido en un "molle" para sacralizar ese pasado donde la naturaleza y el ser humano se integraban en un mismo orden natural (Neale-Silva, p. 313$)^{6}$.

6. El crítico propone además una teoría del hombre y la naturaleza relacionada la filosofía de Feuerbach. 


\section{CONCLUSIÓN}

Estos dos breves relatos muestran dos caras de un mismo autor, pero en el fin observamos una misma intención: manifestar dos vertientes extremas de la raíz de lo humano. En el último relato observamos cómo Vallejo se hermana con otras corrientes contemporáneas al autor como son los nexos "animal-hombre de Jack London y Rudyard Kipling”, tal y como advierte González Vigil en su prólogo a la Poesía Completa (Vallejo, 2012a, p. 51). Esta corriente de narrativa perruna (Subercaseaux, 2014) se separa de la de London, pues no advierte una supuesta superioridad del animal frente al hombre; sin embargo, se hermana con la literatura arguediana que muestra ese continuum, esa empatía (compasión) del nativo con el mundo animal. Esto refrenda la idea de la cosmovisión andina que ambos autores propugnan, particularizando el enlace del mito del indio y su vinculación absoluta con la naturaleza con la que convive. Sin embargo, en Viaje alrededor del porvenir observamos el nexo hombre-máquina, o mejor dicho, la relación ser humano-fábrica, por la concepción mecanizada y lucrativa de la concepción biológica. Se hermana pues con la concepción original de teatro del absurdo. Quizás en la actualidad podamos aseverar que esta última tendencia es la más habitual, en un mundo programado por la tecnología; por tanto, advertimos un autor que ya auguraba el deterioro de lo estrictamente humano en aras de un porvenir económico. No obstante, la esperanza del autor de Poemas humanos en sus últimos días, reside no tanto en otro tipo de modelo económico- aunque se ha criticado abiertamente su "ceguera política"- sino en una solidaridad humana y colectiva que escapa de la lógica de la razón, encaminándose a una defensa radical de la esencia humana, de la concomitancia con la naturaleza.

De todas formas, en cierto modo Vallejo era capaz de vincular la cuestión política y la mística en su poesía. Stephen Hart señala que en la poesía comprometida de Vallejo existe una cierta tendencia a unir la figura del bolchevique con la naturaleza, sobre todo en algunos textos como Gleba, Parado en una piedra..., o Los mineros salieron de la mina. Los problemas sociales adquieren entonces "un sentido universal" (Hart, 1987, p. 50), y provocan un hastío de la propia naturaleza que, tal y como hacían los románticos, entra en consonancia con el ser humano. Como sabemos, ese será el devenir de Vallejo en sus últimos días: un enraizamiento profundo y comprometido con la vida, como nos deja escrito en un verso suelto: "Ser poeta hasta el punto de dejar de serlo" (Vallejo, 2012b, p. 645).

\section{REFERENCIAS BIBLIOGRÁFICAS}

Alazraki, J. (1972). El surrealismo de Tentativa del hombre infinito de Pablo Neruda. Hispanic Review. 40, (1),31-39.

Burga \& Flores Galindo, A. (1979). Apogeo y crisis de la República Aristocrática. Lima: Eds. Rikchay.

Driskel, C. (1978). César Vallejo y el «mito» del indio en un poema de Trilce. Mester, 7 (1), 9-19.

González Montes, A. (2002). Escalas: hacia la modernización narrativa. Lima: Fondo Editorial de la UNMSM.

Flores Galindo, A. (2008). Obras completas III (I). Buscando un Inca: identidad y utopía en los Andes. Lima: Sur Casa de Estudios del Socialismo.

Gómez, N. (2012). Espéculo: Revista de Estudios Literarios, 39. Recuperado en:

http://pendientedemigracion.ucm.es/info/especulo/numero39/chaplinv.html

Higgins, J. (1988). El absurdo en la poesía de César Vallejo. En Antonio Merino (ed.), En torno a César Vallejo. Oviedo: Ediciones Júcar.

Hart, S. (1987). Religión, política y ciencia en la obra de César Vallejo. Londres: Tamesis Book. Neale-Silva, E. (1987). Cesar Vallejo, cuentista. Barcelona: Salvat Editores.

Mariátegui, J.C. (1975). Siete ensayos de interpretación de la realidad peruana. La Habana: Casa de las Américas. 
Oviedo-Pérez de Tudela, R. (2003). La imagen diagonal. De lo cinemático en César Vallejo. Anales de literatura hispanoamericana, (32). 53-70.

Rodríguez-Peralta, P. (1984). Sobre el indigenismo de César Vallejo. Revista Iberoamericana. (127), 429-444.

Sobrevilla, D. (1994). César Vallejo. Poeta nacional y universal y otros trabajos vallejianos. Lima: Amaru Editores.

Subercaseaux, B. (2014). Perros y literatura: Condición humana y condición animal. Atenea. (509), 33-62. Recuperado en:

http://www.redalyc.org/articulo. oa? id $=32831438003$

Vallejo, C. (1976). Obras completas IV: El arte y la revolución. Barcelona: Editorial Laia.

Vallejo, C. (1984). Crónicas I 1915-1926. México: Universidad Nacional Autónoma de México, Dirección General de Publicaciones.
Vallejo, C. (1987). Desde Europa. (Crónicas y artículos de César Vallejo 1923-1938). Prólogo, notas y documentación por Jorge Puccinelli. Lima: Eds. Fuente de Cultura Peruana.

Vallejo, C. (1992). Obras completas. Tomo 11. El arte y la revolución. Prólogo de Ricardo González Vigil. Lima: Editora Perú S.A.

Vallejo, C. (2007). Narrativa Completa. Prólogo de Antonio Merino. Madrid: Akal.

Vallejo, C. (2012a). Narrativa completa de César Vallejo. Lima: Petróleos del Perú.

Vallejo, C. (2012b). Poesía completa de César Vallejo. Lima: Petróleos del Perú.

Villanes, C. (1988). El indigenismo en Vallejo. Cuadernos Hispanoamericanos, 456, 751-760. Yanuzzi-Revetria，C. (2009). César Vallejo y el pitagorismo. Cartaphilus, Revista de Investigación y Crítica Estética. 5,167-170. 